\title{
A EDUCAÇÃO POPULAR EM UMA PERSPECTIVA CONTRA- HEGEMÔNICA: reflexões acerca do Capitalismo e as questões socioambientais
}

\author{
Priscilla Pantoja do Nascimento Brandão ${ }^{1}$ \\ Marcelo Conceição da Rocha Campos ${ }^{2}$ \\ Ângela do Céu Ubaiara Brito ${ }^{3}$
}

\begin{abstract}
RESUMO
O trabalho analisa os desdobramentos socioambientais e mazelas sociais no Igarapé da Fortaleza-AP, decorrentes do projeto ICOMI, fazendo um diálogo com a Educação Popular. Investigou-se quais as contribuições da Educação Popular, como instrumento de emancipação do indivíduo, que podem ser um caminho para atenuar as questões socioambientais naquela região. A metodologia se alicerçou no paradigma qualitativo, subsidiada pela pesquisa bibliográfica. Identificou-se que a ocupação das áreas do Igarapé da Fortaleza-AP, a partir de atividades econômicas, colaborou para o aumento dos problemas socioambientais. O estudo contribuiu para identificar que as propostas de empoderamento popular se configuram como possibilidade para minimizar os problemas sociais.
\end{abstract}

Palavras-chave: Capitalismo. Meio ambiente. Educação Popular. Contrahegemonia. Igarapé da Fortaleza-AP.

\section{POPULAR EDUCATION IN A PERSPECTIVE AGAINST HEGEMONY:}

\section{reflections on capitalism and socio-environmental issues}

\begin{abstract}
The paper analyzes the socio-environmental developments and social problems in the Igarapé of Fortaleza-AP, resulting from the ICOMI project, making a dialogue with Popular Education. It was investigated the contributions of Popular Education, as an instrument of emancipation of the individual, that can be a way to attenuate the socio-environmental issues in that region. The methodology was based on the qualitative paradigm, supported by bibliographical research. It was identified that the occupation of the areas of the Igarapé of Fortaleza-AP, from economic activities, contributed to the increase of socio-environmental problems. The study contributed to identify that the proposals of popular empowerment are configured as a possibility to minimize social problems.
\end{abstract}

Keywords: Capitalism. Environment. Popular education. Counter-hegemony. Igarapé of the fortress-AP.

\footnotetext{
Mestre em Educação, pertencente a linha de Pesquisa de Educação, Culturas e Diversidades, da Universidade Federal do Amapá - UNIFAP. E-mail: prilpe@outlook.com

${ }^{2}$ Graduado em Licenciatura Plena em Letras (2008) pela Universidade Federal do Amapá (UNIFAP), Bacharel em Direito (2015) pela Universidade Federal do Amapá (UNIFAP). E-mail: mcrcap@bol.com.br

${ }^{3}$ Coordenadora da Brinquedoteca da Universidade do Estado do Amapá. Doutora em Educação pela Universidade de São Paulo- USP. E-mail: angela.brito@ueap.edu.br
} 


\section{INTRODUÇÃO}

A partir da década de 1940, ocorrem grandes mudanças na dinâmica espacial amapaense, em virtude da criação do Território Federal do Amapá, o que cristalizou a política do Governo Federal que era a de ocupação espacial, sobretudo na Amazônia e Centro-Oeste, sendo que "com a instituição do Território Federal do Amapá (1943), foram criadas diretrizes políticas e administrativas, infraestruturas e incentivos para o desenvolvimento de atividades econômicas" (PORTO, 2015, p. 24).

Nesse momento, grandes grupos econômicos se instalaram na Amazônia, beneficiados pelas políticas de valorização e desenvolvimento da região, a exemplo da Indústria e Comércio de Minérios S.A. (ICOMI), provocando transformações político-econômicas no Amapá, propiciando a ocorrência de um fluxo migratório, sobretudo para as cidades de Macapá e Santana, de modo que se pode relacionar o crescimento demográfico e a organização espacial do Amapá com o processo de exportação do manganês até a década de 1980 (PORTO, 2007).

Como parte dos imigrantes não conseguiu ingressar no mercado de trabalho, de maneira a serem absorvidos pelos grandes empreendimentos da época, eles foram ocupar, de modo desordenado e em condições precárias, áreas periféricas e alagadas, como a das margens do Igarapé da Fortaleza-AP, pressionando as ressacas por meio da construção de moradias, aterramento, queimadas, despejo de resíduos sólidos e dejetos (TAKIYAMA, 2003).

Frente a esse contexto, este trabalho investiga as questões socioambientais do Igarapé da Fortaleza-AP, provocadas, sobretudo, pelo processo de instalação do Projeto ICOMI no Estado do Amapá, com compreensão do processo de hegemonia, trazendo contribuições para amenizar os impactos socioambientais, sob o viés da Educação Popular. Assim, investigou-se o seguinte problema: quais as contribuições da educação popular, como instrumento de emancipação do indivíduo, que podem ser um caminho para atenuar as questões socioambientais no Igarapé da FortalezaAP, advindas da implantação do projeto ICOMI no Estado do Amapá?

A metodologia fundamentou-se na abordagem qualitativa (MINAYO, 2002), no uso predominante da pesquisa bibliográfica, com base em estudos 
de Figueira (2013), da Pós-Graduação da Universidade Federal do Amapá (UNIFAP), que discute a temática e que permitiu a contextualização do Igarapé da Fortaleza-AP, bem como a análise dos aspectos que possibilitaram a instalação do Projeto ICOMI no Estado do Amapá e as consequências deste para a desordenada ocupação das áreas de ressaca, especificamente a margem do Igarapé da Fortaleza-AP, além de se apresentar um caminho para as questões socioambientais, com base nos paradigmas da Educação Popular.

Ademais, buscou-se fazer uma análise dos estudos já existentes que abordam a presente temática, procurando por palavras-chave, como: Igarapé da Fortaleza; Educação Popular e ICOMI. Complementarmente, ressalta-se que o fato de se conhecer o lócus de pesquisa em questão e vivenciar os problemas do cotidiano, existentes no local, auxiliou também nas análises e diálogos com a teoria e reflexão acerca do objeto da pesquisa proposta.

\section{CONTEXTUALIZAÇÃO DO IGARAPÉ DA FORTALEZA-AP E AS QUESTÕES SOCIOAMBIENTAIS}

O Igarapé da Fortaleza-AP está situado na divisa entre os municípios de Macapá e Santana, sendo que no lado esquerdo da Rodovia Salvador Diniz, na parte pertencente ao município de Macapá, tem-se a Área de Preservação Ambiental (APA da Fazendinha), localizada no Distrito da Fazendinha; já, do outro lado, no município de Santana, há a presença de uma área reconhecidamente urbana, chamada de bairro Fortaleza.

O percurso para adentrar no Igarapé da Fortaleza-AP pode ser feito tanto por via terrestre, quanto por via fluvial. O acesso por via terrestre pode ser feito por meio das rodovias AP-010 e AP-070, responsáveis pela ligação dos municípios de Macapá e Santana. Já por via fluvial, o acesso pode ser realizado por meio do Igarapé da Fortaleza, este que é também uma saída para o Rio Amazonas (AGUIAR, 2003).

Pelo fato de apresentar uma extensão considerável, o lgarapé da Fortaleza pode ser utilizado também para a navegação (TAKIYAMA, 2003), possibilitando a entrada de barcos e balsas das mais diversas localidades do próprio Estado do Amapá, bem como das regiões ribeirinhas do Estado do 
Pará, configurando-se como rota estratégica para a circulação de pessoas e comercialização de mercadorias.

O censo do Instituto Brasileiro de Geografia e Estatística (IBGE), de 2010 registrou uma população de 6.185 habitantes no Igarapé da Fortaleza-AP, de maneira que o lado que fica situado no município de Macapá comporta 2.063 habitantes, e 4.122, já ficam no lado do município de Santana. Segundo esse censo, grande parte da população do Igarapé da Fortaleza-AP é proveniente das ilhas ribeirinhas do vizinho Estado do Pará, que veio para cá, principalmente em busca de novas oportunidades, com vistas a conseguir melhorias na qualidade de vida.

A atividade econômica dos moradores do Igarapé da Fortaleza-AP que até 1995 se restringia, basicamente, ao extrativismo, à pesca, ao comércio e aos estaleiros, passou a apresentar uma nova configuração a partir de 2000, com as principais atividades econômicas ligadas os setores: primário, a exemplo de agricultura, pesca artesanal, pecuária bovina; o secundário, com a presença de pequenas olarias; e o terciário, com a venda de gêneros alimentícios, além da comercialização feita em bares e restaurantes (CUNHA et al, 2003).

Impende registrar uma atividade que chama a atenção naquele ambiente e que ainda é praticada por algumas famílias na comunidade, que é a carpintaria naval, com a produção e reforma de pequenas embarcações em estaleiros a céu aberto, de maneira artesanal. Há três estaleiros no local, que fazem uso de madeira oriunda do Estado do Pará, do Amazonas e do interior do Amapá, numa profissão empírica, a qual passa de geração para geração, e que hoje está em declínio, em virtude da preferência dos clientes por embarcações feitas de ferro e alumínio, cuja durabilidade é maior.

O Igarapé da Fortaleza-AP é interligado por inúmeras ressacas ecossistema típico da zona costeira do Amapá -, tanto do município de Macapá quanto do município de Santana, e é justamente nessas áreas que se observa uma intensa ocupação urbana desorganizada, tanto por habitações quanto por instalações de atividades, culminando com um cenário de desequilíbrio ambiental, o que resulta na perda de biodiversidade nesse espaço, com a produção de resíduos poluentes que afetam a vida dos moradores da localidade. 
Avista-se, no Igarapé da Fortaleza, a degradação dos recursos naturais, resultado da expansão desordenada, com a edificação de pontos comerciais e residências, o que provocou o desmatamento da área, poluição do rio, redução da biodiversidade e outros malefícios. Segundo Bastos (2010, p. 30), não há dúvida de que a construção de casas nessas áreas se defronta com problemas de infraestrutura, falta de saneamento e abastecimento de água, além de que a ausência de uma rede coletora de esgoto "obriga os moradores a utilizar fossas negras rasas para armazenamento do esgoto sanitário, as quais contaminam substancialmente os mananciais do Igarapé da Fortaleza".

A problemática ambiental é diversa naquele local. Bocato Júnior (2009, p. 20) aponta que se trata de um ambiente que se apresenta como:

[...] um ativo natural frágil e sujeito a diversos riscos de degradação ambiental. Em consequência disso, há ocupação desordenada do solo e pressão imobiliária. Já o lançamento de lixo e esgoto na Foz do Rio Amazonas são percalços desses impactos. Também é comum a presença de navios de grande porte ancorados no entorno da APA, os quais aguardam para ancorar no Porto de Santana-AP. Existe ainda a possibilidade de que tais embarcações façam a troca da água de lastro nestes locais, potencializando o risco de contaminação das águas do rio e também o risco de vazamento de óleo.

\section{TRANSFORMAÇÕES POLÍTICO-ECONÔMICAS NO AMAPÁ COM A IMPLANTAÇÃO DO PROJETO ICOMI}

No contexto de um País como o Brasil, que ainda enfrenta diversas problemáticas sociais, como a disparidades entre classes, Mclaren e Farahmandpur (2002, p. 29) advertem que:

o período pós-Segunda Guerra tem testemunhado a crescente concentração e centralização do poder social, político e econômico nas mãos de um número relativamente pequeno de oligopólios.

De fato, a possibilidade de explorar o manganês no Amapá, é um exemplo daquilo que somente atende a pequena parcela de classes mais abastadas, donas dos meios de produção. Nesta direção, no período da guerra fria, a indústria bélica que precisava de aço em demasia, pôs o Brasil como 
centro das atenções do mercado internacional, sendo alvo de muitos grupos econômicos.

A dinâmica espacial amapaense, a partir da década de 1940, sofreu grandes mudanças, decorrentes da criação do Território Federal do Amapá, o que consumou a política do Governo Federal que, à época, era a de ocupação espacial, sobretudo na Amazônia e Centro-Oeste, de maneira que a partir da “instituição do Território Federal do Amapá (1943), foram criadas diretrizes políticas e administrativas, infraestruturas e incentivos para o desenvolvimento de atividades econômicas" (PORTO, 2015, p. 24).

A descoberta de uma das maiores jazidas de manganês do Brasil, próxima da região em Serra do Navio, logo após a criação do Território Federal do Amapá, viabilizou a implantação do Projeto ICOMI no Amapá. A instalação do referido projeto "foi a primeira experiência de mineração industrial na Amazônia. O empreendimento foi conduzido pela Indústria e Comércio de Minérios S.A. (ICOMI), que se instalou na região na década de 50 do século XX" (MONTEIRO, 2003, p. 114).

A ICOMI foi autorizada pelo governo, em 1953, a explorar o manganês pelo período de 50 anos - de 1953 a 2003 - e, por meio da parceria com a mineradora americana Bethlem Steel, iniciou a atividade manganesífera, investindo maciçamente na construção de uma infraestrutura "que compreenderam as instalações industriais para a lavra e o beneficiamento do minério, a estrada de ferro e um embarcadouro de minério. No ano seguinte, a ICOMI iniciou a construção e a urbanização de duas vilas residenciais: Serra do Navio e Amazonas" (MONTEIRO, 2003, p. 121).

A intensificação da produção mineral nesse período contribuiu sobremaneira para a aceleração do processo de ocupação populacional, com a vinda de pessoas atraídas pelas ofertas de emprego desse grande projeto econômico, o que provocou uma transformação do espaço geográfico amapaense, principalmente nos municípios de Macapá e Santana. Segundo Porto (2007, p. 67):

A ocupação pela população desta região no contexto nacional cresceu, dada a participação do Estado na Amazônia após a década de 1960, investindo em infraestruturas (usinas hidrelétricas, rodovias, portos) e equipamentos, bem como oferecendo incentivos fiscais e financeiros; e incentivando a 
migração, tendo sido esta última incentivada por outros fatores, tais como: descoberta de novos garimpos e de grandes jazidas minerálicas; extrativismo madeireiro; implantação de montadoras na Zona Franca de Manaus; e a instalação de Grandes Projetos [...]

Santos (2009, p. 35) corrobora com essa ideia, asseverando que a região amazônica, com a instalação de grandes grupos econômicos, passa a receber enormes contingentes populacionais, em especial nordestinos; todavia, não possui um espaço rural adequado economicamente e com infraestrutura, para abrigar essa população que, em virtude disso, passa a se direcionar para os principais núcleos regionais. Como consequência, houve um fenômeno de crescimento e inchaço populacional das principais cidades amazônicas.

Na mesma direção, Takiyama (2003, p. 5) também evidencia:

[...] Consolidando as ocupações, começam a ser feitas ligações clandestinas de energia elétrica e água para abastecer as residências. Em algumas situações, o próprio poder público financia estas pequenas obras, no intuito imediatista de melhorar as condições de vida dessas populações. Fixado o núcleo habitacional, as pressões ambientais crescem em proporções evidentes. Sem um sistema de coleta, acumulamse entulho e lixo. A falta de saneamento básico agrava a situação, com dejetos sendo atirados nas águas das ressacas. Todo esse processo resulta na destruição de um importante patrimônio natural e de um ambiente que possui várias funções ambientais (controle de enchentes, alimentação dos reservatórios de água subterrânea, controle do clima, manutenção da biodiversidade), sociais ( uso para recreação e turismo, preservação da identidade cultural) e econômicas (oferta de produtos (como plantas medicinais e pescados).

Resta evidente que a ocupação acelerada dessas áreas, gera desequilíbrios em larga escala, em diversos âmbitos, caracterizando um processo de assenhoreamento impróprio para o local. A ocupação dessas áreas se dá, sobretudo por pessoas de baixa renda, imigrantes "oriundos de comunidades ribeirinhas, habituados, portanto a estabelecer residências, próximo às águas" (TAKIYAMA 2003, p. 5).

Logo, a instalação da ICOMI tem relação intensa com o crescimento demográfico e a organização espacial do Amapá, bem como apresenta reflexos na distribuição da população urbana e rural, cujas mudanças foram mais sentidas em Macapá e Santana. Além de propiciar o alargamento dos 
limites urbanos do Amapá, a ICOMI foi responsável, conforme aponta Porto (1999), pela maior parte das receitas do ex-Território Federal do Amapá por quase 45 anos, considerando que a fatia maior da arrecadação do Executivo, à época, provinha dos tributos ligados à exploração do manganês.

A instalação de algumas empresas no Brasil, a exemplo da ICOMI, teve a participação decisiva do capital estrangeiro na sua implementação, não com a intenção de propiciar bem-estar para a coletividade e satisfazer as necessidades básicas das pessoas, e sim objetivando a ampliação incessante do lucro do projeto capitalista, usando práticas e técnicas ambientais consideradas nocivas. Nessa esteira, assevera Michel Parenti (apud MCLAREN; FARAHMANDPUR, 2002, p. 44):

\begin{abstract}
O capitalismo é um sistema sem alma, sem humanidade. Ele tenta reduzir cada atividade humana à lucrabilidade do mercado. Ele não tem fidelidade para com a democracia, para com os valores da família, ética judeu-cristã, cidadãos comuns ou qualquer dos outros grupos que são abocanhados por seus representantes de relações públicas em ocasiões especiais. Ele não tem fidelidade com qualquer nação; ele é fiel apenas ao seu próprio sistema de acumulação de capital. Ele não é dedicado para "servir à comunidade"; ele serve somente a si mesmo, extraindo tudo o que pode dos muitos de forma que pode dar tudo a poucos.
\end{abstract}

Mesmo com o usufruto de grande prosperidade, a partir do fim da Guerra Fria, a ICOMI passou a conviver com o processo de decadência, encerrando suas atividades em dezembro de 1997, com um saldo negativo de desemprego e degradação ambiental - desmatamento, destruição do solo, assoreamento de cursos de água e deposição a céu aberto de estéril e rejeitos (DRUMMOND; PEREIRA, 2007, p. 427). Após a paralisação das atividades, parte dos trabalhadores, não dispondo de outra opção, retornou para seus locais de origem ou emigrou para as cidades de Macapá e Santana.

A concentração populacional acentuou-se, com maior vulto, na região sudeste do Estado, de forma que a falta de condições socioeconômicas e o déficit habitacional, resultou no uso das áreas de ressaca para habitação, representando sérios problemas para aqueles que, sem alternativa, são compelidos a morar nesses espaços (PORTILHO, 2000, p. 13). Tal situação impulsionou parte de grupos populacionais de baixa renda, que ocuparam, inadequadamente, as áreas do entorno Igarapé da Fortaleza-AP. 
O processo de ocupação das áreas de ressaca, com o estabelecimento de moradia em áreas sem nenhuma infraestrutura, sobretudo na região do Igarapé da Fortaleza-AP -, motivada, como visto anteriormente, entre outras coisas, pela emigração de trabalhadores após o fim das atividades da ICOMI, gerou inúmeros impactos socioambientais, que ainda podem ser agravados pelo constante aumento no número habitantes na área. Figueira (2013) aponta que, hoje, parte dos problemas ambientais do lgarapé da Fortaleza estão ligados à degradação ambiental, quais sejam: lixo a céu aberto, poluição das águas, aumento de ratos e de baratas, além de esgoto a céu aberto. Além disso, nas margens do local, é possível observar a redução da mata nativa, a erosão e a poluição do solo.

Fica evidente também que, grande parte dos moradores, vive em condições sociais deploráveis, com precárias instalações de saneamento básico, e sem a mínima infraestrutura, demonstrando um ambiente no qual os sujeitos são obrigados a viver à margem da sociedade e tendo que se adequar às problemáticas sociais postas. Além disso, observa-se uma notória ausência de ações do Poder Público no local, cristalizadas, por exemplo, na inexistência de uma Unidade Básica de Saúde para atender os moradores e na falta de uma delegacia para atender as ocorrências dentro da área, deixando a população sem respostas rápidas para suas demandas cotidianas.

\section{A EDUCAÇÃO POPULAR COMO INSTRUMENTO EMANCIPATÓRIO}

Percebe-se, nesse contexto, que com o processo de globalização cada vez mais vigoroso, a sociedade tende a se expandir, tomando diversos delineamentos. O estado e a publicidade (produzida, sobretudo no seio de grandes empresas multinacionais, a fim de multiplicar suas vendas e ampliar os lucros) aumentam progressiva e violentamente, uma falsa necessidade de consumo, por meio do marketing característico do Capitalismo.

Os indivíduos, sentindo-se coagidos a uma vida circunscrita ao consumismo, migram, para que possam atender às suas novas necessidades, criadas pelo mundo globalizado. Atraindo-se cada vez mais pessoas para as cidades sem o devido planejamento, ocorre como consequência o inchaço 
populacional em determinadas áreas, intensificando-se as desigualdades e diversos problemas de ordem social, característicos da divisão de classes.

Nesse cenário, desencadeiam-se, principalmente, questões relativas à má qualidade de vida, trabalhos e moradias insalubres, problemas de saúde coletiva, entre outros. Considerando que a mudança de realidade social denota a imposição do consumo e o crescimento desordenado, a falta de políticas públicas mostra, claramente, a ausência de preocupação e planejamento por parte do estado e das grandes corporações e acabam por sujeitar a população a viver em moradias irregulares, não planejadas, propagando desequilíbrios sociais e ambientais para esses grupos que se encontram marginalizados.

O cotidiano dessas comunidades acaba se desdobrando em verdadeiros conglomerados que, sem água encanada, sem coleta de lixo ou rede de esgoto, geram riscos de vida em condições subumanas de habitação, além da exclusão social. Essa população, sem alternativas e sem perspectiva de melhoria da qualidade de vida, à medida que as desigualdades vão se procrastinando, também vai naturalizando essa condição de subsistência.

Aqueles que, cotidianamente, estão no âmago da questão, sobretudo, e pela força das necessidades, acostumam-se a viver sem uma infraestrutura adequada e nessas condições desfavoráveis, além de acabarem sendo alienados pela falsa ideia de que a desigualdade social é um fenômeno universal, e que nada resta fazer a não ser aceitar a situação em que se encontram.

Mas, como nem tudo é hegemonia, esse processo também traz consigo um grande desafio para esses indivíduos: o de se perceberem como pagantes desse processo, que compreende várias formas de engrandecimento para uns e de segregação para outros. Trata-se de compreender a existência de um movimento de evolução do ser humano, que diz respeito à compreensão da própria realidade em que os sujeitos estão inseridos. Mas, sob outra perspectiva, esse processo também pode ter outro significado, aquele que gera declínios, retrocessos à sua própria existência, além de afetar negativamente a vida das populações posteriores. À vista disso, Buarque (1990 apud NOAL, 2000, p. 67) afirma: 
Os riscos que se apresentam à humanidade, criados pela civilização, restituem ao homem a aventura de retomar seu destino e controlá-lo. O que ele antes fazia temendo aos deuses aos quais já não teme, com medos das pragas, que já controla, submetido ao desconhecido, que já conhece, agora 0 homem terá que fazer diante dos riscos que criou. Terá que enfrentar um deus maluco chamado HOMEM, uma praga chamada poder científico e tecnológico e tentar desvendar um desconhecido chamado ele mesmo, seu sistema econômico, sua relação com a natureza, a essência de seu processo civilizatório.

Nesse sentido, os diversos acontecimentos históricos, decorrentes das necessidades sociais, ocasionaram também mudanças vigorosas no segmento educacional. Nessa lógica, em uma proposta contra-hegemônica, incorporada às práticas decoloniais, a educação popular surge com o intuito de apresentar uma nova proposta educativa, fruto de grande inconformação da realidade social que privilegia alguns grupos em detrimento de outros. A educação popular, então, manifesta-se em contraposição a todas as práticas educacionais transmissivas, fundamentada nas necessidades do povo e almejando uma transformação da realidade social.

Para Freire (2002, p. 48), uma das alternativas de superação desse estado de decadência é a obstinação, assegurando que é necessário:

desafiar os grupos populares para que percebam, em termos críticos, a violência e a profunda injustiça que caracterizam sua situação concreta. Mais ainda, que sua situação concreta não é destino certo ou vontade de Deus, algo que não pode ser mudado.

Freire (2002) continua corroborando que uma das questões essenciais com que as pessoas devem se preocupar é a impulsão de posturas rebeldes em modos revolucionários de fazer e agir que engajam os indivíduos em um procedimento radical de revolução do mundo. A rebeldia é ponto de partida imprescindível, é combustão da justa ira, mas não é suficiente. A rebeldia enquanto denúncia necessita se alongar até uma posição mais radical e crítica, a revolucionária, fundamentalmente anunciadora. A transformação do mundo demanda dialetização no que tange a denúncia da situação desumanizante na qual a população se encontra e o anúncio de superação. 
Na esteira de Gadotti (2008), compreende-se que se faz necessário educar para a sustentabilidade, de forma que, os indivíduos que vivem da terra e a ela pertencem, devem buscar melhoria da qualidade de vida por meio da ecopedagogia, pois, acredita-se que a transformação e o desenvolvimento provêm de uma educação ambiental alicerçada no desenvolvimento sustentável por meio de uma sensibilização ecológica na maneira de como pensamos e agimos com nosso planeta. É prudente esse diálogo, considerando-se o desordenamento dos modos de vida e produção, e com isso a necessidade de almejar soluções de problemas relacionados aos desequilíbrios ambientais que são vivenciados nos dias atuais.

Também em Boff (1999) depreende-se que tudo aquilo que existe e vive, necessita ser cultivado para continuar a existir e a viver, seja uma planta, um animal, uma criança, um idoso, o planeta terra. Uma antiga fábula diz que a essência do ser humano reside no cuidado, e que este é mais fundamental do que a razão e a vontade. Assim, a ótica de cuidados é capaz de fazer nascer no homem uma nova ética mais descomplicada para todos, criando possibilidades de inspiração para uma emancipação comunitária e inclusão social.

Assim, a Educação Popular possibilita a compreensão do todo a partir de uma educação que está voltada para a vida, para um convívio harmonioso, democrático e justo. Estes são alguns dos efeitos de uma Educação Popular autêntica e bem fundamentada. Essa educação informal também forma, liberta, educa e aperfeiçoa. As práticas, as experiências vividas são sempre um aprendizado, nunca inferior ao aprendizado científico, pois, no ponto de vista de sua totalidade, o maior desafio de um ser humano é se descobrir, viver em plenitude e isto independe de classe social, de conhecimento científico ou de capital.

A Educação Popular é, portanto, todo compartilhamento de conhecimento que subsidia um processo de aprendizagem em comum, dando voz e vez a cada um dos indivíduos, empoderando-os a enfrentar as mais variadas formas de opressão para lutar por uma sociedade mais consciente de seus direitos e solidária. É importante aproveitar o conhecimento local, a aproximação com a população e partir do cotidiano para a educação popular se alicerçar em uma construção coletiva. 
Silva (2008, p. 149) compreende a Educação Popular como:

uma prática que, independente dos espaços - formais, governamentais, não governamentais, alternativos - nos quais se concretiza, se afirma como uma metodologia orgânica, coletiva e cooperativa que potencializa as condições de captação, apreensão e leitura crítica da realidade e de intervenção dos protagonistas dessa ação educativa na esfera social (econômica, política, cultural), objetivando transformá-la.

Tem-se, desse modo, que a Educação Popular pode ser observada como uma possibilidade educativa incentivada não só pelo Estado, como também por partidos políticos, sindicatos, organizações não-governamentais e outras instituições. Trata-se de uma ferramenta de luta, manuseada, sobretudo, pelas classes trabalhadoras. Floresceu dentro das práticas anarquistas do início do século XX e se manifestou na política educacional do governo, a partir dos anos de 1930, no seio de projetos voltados para a educação do povo.

Gadotti (2012) descreve a Educação Popular como representação dos movimentos sociais, sustentando a esperança, com suas múltiplas subjetividades políticas, na luta por direitos humanos, por uma vida digna, alicerçando-se nas forças democráticas de poder local. Destarte, a educação popular dá suporte para que a segregação seja percebida por aqueles que fazem parte dela e, a partir daí, fortalece os movimentos populares, desmascara as utopias de dependência, conduzindo um debate que preconiza as teorias da libertação e a pedagogia dialética.

Freire e Nogueira (1991, p. 19) estabelecem uma relação entre a prática da Educação Popular e o exercício da cidadania ao se manifestarem, dizendo: "[...] entendo a educação popular como o esforço de mobilização, organização e capacitação das classes populares; capacitação científica e técnica". Portanto, trata-se de uma busca incansável pelo empoderamento popular através do engajamento do povo, da organização política da sociedade, do enfrentamento, buscando o rompimento das relações de submissão e opressão.

Dentro dessa ótica, o próprio Freire (1992, p. 126) estabelece como tarefa da Educação Popular, não só antigamente como também nos tempos atuais, buscar: 
[...] por meio da compreensão crítica de como se dão os conflitos sociais, ajudar o processo no qual a fraqueza dos oprimidos se vai tornando força capaz de transformar a força dos opressores em fraqueza. Esta é a esperança que nos move.

A Educação Popular se firmou como paradigma através de suas grandes intuições, a exemplo da concepção da educação como produção e não simplesmente como transmissão mecânica do conhecimento; a refuta ao autoritarismo, à manipulação, à ideologização; a defesa da educação como um ato de diálogo na construção rigorosa e também imaginativa do conhecimento, da razão de ser das coisas; a noção de uma ciência plenamente aberta às necessidades populares e de um planejamento comunitário, democrático e participativo (GADOTTI; TORRES, 2003).

Portanto, as ações no campo da Educação Popular rumam para uma transformação da sociedade, ofertando a melhoria na qualidade de vida das classes marginalizadas. Pautada numa concepção dialética, essa educação emancipatória ocorre num contexto dinâmico em que educador e educando aprendem juntos; onde não há transmissão de conhecimento, já que os saberes são construídos no cotidiano e na própria prática pedagógica (FREIRE, 1967).

\section{ANÁlise dO CONTEXTO DO IGARAPÉ DA FORTALEZA E A EDUCAÇÃO POPULAR}

As análises bibliográficas nos estudos de Figueira (2013), demonstram que as disparidades sociais presentes no contexto do Igarapé da Fortaleza, são apenas mais um retrato da negligência e falta de comprometimento por parte do estado com a população, assim como acontece em diversos outros setores, pois o autor afirma que os aglomerados subnormais são advindos da necessidade do ser humano fixar residência próximo aos mananciais de água, provenientes da má divisão de renda verificada em todo país e, em especial, no Estado do Amapá, ocasionando, em sua estrutura, as demais mazelas para o indivíduo e para o ambiente, afrontando ao princípio constitucional da dignidade da pessoa humana, além de ofender o fundamento dos Direitos Humanos. 
Com o andamento das análises, por meio dos estudos de Porto (1999; 2007; 2015) Takiyama (2003), Drummond e Pereira (2007) e Figueira (2013), foi possível associar a sucessão de impactos que a população sofre, diretamente relacionadas às intervenções feitas pelo sistema capitalista. Concomitante ao entendimento desses autores, Mota Neto (2015) dialoga acerca das implicações da educação popular libertadora no cenário atual, bem como seu processo de readaptação, na empreitada pela independência, pela libertação.

Nesse contexto, a Educação Popular é vista como uma pedagogia da insubordinação, da revolta, que expressa exatamente no eixo da inquietação e insatisfação com a realidade social que está imposta. Uma proposta revolucionária, em busca da transformação da sociedade. A educação popular coopera, no sentido de se contrapor às mais variadas configurações de opressão delineadas pela história, sejam elas violência física ou simbólica, capitalismo, opressão ou imposição de submissão disfarçada.

De acordo com Figueira (2013), também foi possível perceber que há certa percepção socioambiental feita pelos próprios sujeitos pertencentes à comunidade, acerca da existência das problemáticas de seu habitat, que envolve as questões de saúde pública, especialmente, no que tange à moradia, saúde, ecologia, trabalho. Essa percepção se dá, principalmente, por meio da mídia, em segundo lugar está à educação, na figura da escola e do professor. Contudo, embora existam esses meios de informação, acredita-se que os habitantes do aglomerado pesquisado 'carecem' que estas informações sejam mais direcionadas, especialmente dentro da comunidade e com a participação do governo, das entidades privadas e da própria liderança da comunidade local, para o fim de se formar políticas públicas voltadas para minimizar os problemas socioambientais, indicados pelos próprios habitantes (FIGUEIRA, 2013).

Para Mota Neto (2015), Educação Popular procura envolver tudo aquilo que parte da realidade do povo, abrindo caminhos para a decolonialidade. $O$ ponto de partida da educação popular é a realidade do povo e sua leitura crítica, construindo o empoderamento daqueles que estão à margem a sociedade, construindo mediações educativas e considerando a cultura, as vivências dos diferentes grupos humanos. 
Portanto, no contexto da comunidade do Igarapé da Fortaleza-AP, a Educação Popular pode servir como cenário de assuntos ligados ao povo, suas problemáticas e sua autocrítica, refundamentando-se de acordo com os acontecimentos históricos e as suas influências. A educação popular é significativa nesse processo de refundamentação dos sujeitos, no sentido de descortinar as ideias de compreensão da hegemonia, do capitalismo e os conflitos entre as classes mais abastadas e o povo.

Essas discussões se fazem necessárias e fundamentais, no reconhecimento dos indivíduos por si mesmos, como padecentes do processo, pois munem a população de movimento e inquietação, e mune também no recrutamento de combatentes nessa empreitada de guerra entre estado e a população, entre elite e massa, sobretudo no que tange às populações menos favorecidas, no qual a partir do que se apresenta, o lugar assemelha-se a locais distantes, onde a cidadania quase não chega, uma vez que os indivíduos sentem na pele o descaso e a falta de compromisso do estado para com a infraestrutura e qualidade de vida desses cidadãos, se é que assim podem ser chamados, diante da situação em que se encontram.

O desfecho das análises indica que os problemas socioambientais existentes em nossa sociedade, frequentemente, são desdobramentos que têm muito a ver com os interesses de certos grupos em satisfazer interesses individuais, exercendo poder político, cultural e econômico sobre outras populações, sem pensar nas implicações negativas que a incoerência de tais práticas traz. Ressalta-se, aqui também, uma profunda contribuição, no que diz respeito à reflexão e o diálogo acerca das relações sociais desiguais, o descortinamento de aspectos que, muitas vezes, ficam na penumbra, na invisibilidade, que acabam mantendo um cenário de corpulenta vulnerabilidade econômica e social.

Ademais, para que seja possível uma transformação da realidade, é necessário lutar por ela, manter a esperança e crer que as pessoas que constituem a comunidade do Igarapé da Fortaleza-AP têm capacidade de intervir e modificar o seu contexto. Urge, assim, a efetivação de ações, práticas e intervenções naquele local, advindas da problematização da realidade posta, que deve ser realizada pelos próprios sujeitos. 
Nesse sentido, numa perspectiva futura, intenta-se a realização de uma prática pedagógica, através de uma metodologia que incentiva a participação social e a emancipação humana - estimulando os partícipes a pensarem sobre o ambiente vivido, a falarem de suas vivências, a visualizarem e refletirem sobre as causas dos problemas existentes -, de maneira a estimular os agentes envolvidos a apontarem possíveis soluções para os problemas evidenciados, com vistas à transformação.

\section{CONSIDERAÇÕES FINAIS}

A proposta deste estudo se pautou em uma análise bibliográfica de natureza reflexiva, objetivando a compreensão da realidade socioambiental da comunidade do Igarapé da Fortaleza-Ap. Muitos são os desafios colocados diante do processo de hegemonia, que é imposto todos os dias à massa da população. Contextualizou-se, historicamente, a vinda da ICOMI para o Amapá que, ao explorar e extrair as riquezas do estado, trouxe benefícios para as classes privilegiadas, e os danos foram pagos pela população em forma de mazelas, como: a miséria e a ocupação desordenada, trazendo ainda, até mão de obra barata de outros estados, sem se preocupar com o bem-estar desses indivíduos, configurando-se como parasitas para a sociedade amapaense.

Nesse sentido, a educação popular auxiliou no processo de compreensão da orientação ideológica, estimulando a busca de atividades educativas, libertação e subsidiando o autodesenvolvimento da massa da população. No seio da educação popular libertadora, entende-se esta como uma experiência, uma prática, mas ao mesmo tempo um processo de luta, uma ideologia, que busca por meio do empoderamento das massas, romper com a divisão de classes.

O capitalismo é uma teia problemática que, para se manter no poder, 'lança mão' da exploração e opressão, onde os trabalhadores produzem muito mais para os outros do que para si, e com pouco se conformam, na ideia de que é um caminho natural, por não possuírem os patrimônios. Dessa forma, a estrutura política e empresarial se perpetua, configurando-se como instrumento de reprodução de desigualdade, pelo controle e funcionamento estarem sempre sob controle das classes elevadas. 
Portanto, a busca pelo fim dessa enfermidade, pauta-se em ideias revolucionárias de desconstrução, formadas pelas próprias classes excluídas. Essa empreitada pode ser considerada romântica, uma vez que a celeridade do sistema é violenta. Mas é possível, ser articulada, se tiver como base os interesses mútuos e compartilhados, o que não se pode é desistir, cruzar os braços e assistir cada vez mais que as injustiças sejam disseminadas escancaradamente. Pois, se há avanço histórico, ele só foi conseguido por meio de muita luta, partindo dos sujeitos mais interessados nessa transformação. 


\section{REFERÊNCIAS}

AGUIAR, Josiane do Socorro et al. Caracterização e Avaliação das Condições de Vida das Populações Residentes nas Ressacas Urbanas dos Municípios de Macapá e Santana. In: TAKIYAMA, L. R.; SILVA, A. Q. da (Org.). Diagnóstico das ressacas do estado do Amapá: bacias do lgarapé da Fortaleza e Rio Curiaú, Macapá: CPAQ/IEPA; DGEO/SEMA, 2003. p. 165-230.

BASTOS, Argemiro Midonês. Modelagem de Escoamento Ambiental como Subsídio à Gestão de Ecossistemas Aquáticos no Baixo Igarapé da Fortaleza-AP. 2010. 118 f. Dissertação (Mestrado em Biodiversidade Tropical) - Universidade Federal do Amapá, Amapá.

BOCATO JUNIOR, Francisco Carlos. Valoração Econômica de Ativos Naturais Urbanos: o Caso da Área de Preservação Ambiental da Fazendinha e seu Entorno, Macapá-Amapá. 2009. 101 f. Dissertação (Mestrado em Biodiversidade Tropical) - Universidade Federal do Amapá, Amapá.

BOFF, Leonardo. Saber cuidar: ética do humano - compaixão pela terra. Petrópolis: Vozes, 1999.

CUNHA, Alan Cavalcanti da et al. Estudo preliminar sobre a variação espaçotemporal de parâmetros de qualidade de água no lgarapé da Fortaleza. In: TAKIYAMA, L. R.; SILVA, A. Q. (Org.). Diagnóstico das ressacas do estado do Amapá: bacias do Igarapé da Fortaleza e Rio Curiaú, Macapá: CPAQ/IEPA; DGEO/SEMA, 2003. p.105-136.

DRUMMOND, José Augusto; PEREIRA, Mariângela de Araújo Póvoas. 0 Amapá nos tempos do manganês: um estudo sobre o desenvolvimento de um estado amazônico - 1943-2000. Rio de Janeiro: Garamond, 2007.

FIGUEIRA, Sérgio Sampaio. Percepções socioambientais narradas pelos habitantes do aglomerado subnormal do Igarapé da Fortaleza-AP. 2013. 123 f. Dissertação (Mestrado em Direito Ambiental e Políticas Públicas) Universidade Federal do Amapá, Macapá.

FREIRE, Paulo. Pedagogia da autonomia: saberes necessários à prática educativa. São Paulo: Coletivo sabotagem, 2002.

Pedagogia da esperança: um reencontro com a pedagogia do oprimido. Rio de Janeiro: Paz e Terra, 1992.

Terra, 1967.

Educação como Prática da Liberdade. Rio de Janeiro - RJ: Paz e

; NOGUEIRA, Adriano. Que fazer: teoria e prática em educação popular. 3. ed. Petrópolis, RJ: Vozes, 1991.

GADOTTI, Moacir. Educação popular, educação social, educação comunitária: conceitos e práticas diversas, cimentadas por uma causa comum. Revista diálogos, Brasília, 2012. Disponível em: 
<https://portalrevistas.ucb.br/index.php/RDL/article/view/3909/2386>. Acesso em: 26 jul. 2017.

Educar para sustentabilidade: uma contribuição à década da educação para o desenvolvimento sustentável. São Paulo: Ed. L, 2008. (Série Unifreire 2).

; TORRES, Carlos A. (Org.). Educação Popular: utopia latinoamericana. 2 ed. Brasília: Ibama, 2003. INSTITUTO BRASILEIRO DE GEOGRAFIA E ESTATÍSTICA (IBGE). Censo demográfico 2010: resultado do universo. Rio de Janeiro: IBGE, 2011. 1 CD ROM.

MCLAREN, Peter; FARAHMANDPUR, Ramin. Pedagogia revolucionária na globalização. Rio de Janeiro: DP\&A, 2002.

MINAYO, Maria Cecília de Souza (org.). Pesquisa social: teoria, método e criatividade. Petrópolis-RJ: Vozes, 2002.

MONTEIRO, Maurílio de Abreu. A ICOMI no Amapá: meio século de exploração mineral. Novos Cadernos NAEA, Belém, v. 6, n. 2, p. 113 -168, dez. 2003.

MOTA NETO, João Colares da. Educação popular e pensamento decolonial latino-americano em Paulo Freire e Orlando Fals Borda. 2015. 370 f. Tese (Doutorado em Educação) - Universidade Federal do Pará, Belém.

NOAL, Fernando, Oliveira. Os ritmos e riscos: considerações sobre a globalização, ecologia e contemporaneidade. In: LOUREIRO, Carlos, Frederico et al. Sociedade e meio ambiente: a educação ambiental em debate. São Paulo: Cortez, 2000.

PORTILHO, Ivone dos Santos. Áreas de ressaca e dinâmica urbana em Macapá/AP, 2010. Disponível em: <http://www.uc.pt/fluc/cegot/VISLAGF/actas/tema4/ivone> Acesso em: 26 jul. 2017.

PORTO, Jadson Luís Rebelo. Condicionantes para execução de ajustes espaciais no Amapá-Brasil: da gênese de um ente federativo às novas configurações territoriais (trans)fronteiriço. Aldea Mundo-Revista sobre Fronteras e Integración [online], v. 20, p. 21-32, 2015. Disponível em: <http://www.redalyc.org/pdf/543/54343963003.pdf>Acesso em: 27 jul. 2017.

. Condicionantes para execução de ajustes espaciais no Amapá-Brasil: da gênese de um ente federativo à novas configurações territoriais (trans)fronteiriço. Aldea Mundo, Revista sobre Fronteras e Integración, v. 20, p. 21-32, 2015.

. ; COSTA, Manoel Augusto. A Área de livre comércio de Macapá e Santana: questões geoeconômicas. Macapá: O Dia S.A.,1999. 
Amapá: principais transformações econômicas e institucionais - 1943 a 2000. 2. ed. Macapá: GEA/SETEC, 2007.

SANTOS, Antônio Carlos Rodrigues dos. Geografia do Amapá: A (Re) produção do Espaço Amapaense e seus Contrastes. Macapá: Produção Independente, 2009.

SILVA, Rita de Cássia Curvelo da. Educação Popular e Práxis: a Ação Política e Educativa dos Trabalhadores e das Trabalhadoras do MST. In: ROSAS, Agostinho da Silva (org.). Educação Popular: Enunciados Teóricos. Vol. 2. João Pessoa: Editora UFPB, 2008.

TAKIYAMA, Luís Roberto et al. Qualidade das Águas das Ressacas das Bacias do Igarapé da Fortaleza e do Rio Curiaú In: TAKIYAMA, L.R.; SILVA, A.Q. da (Org.). Diagnóstico das ressacas do estado do Amapá: bacias do lgarapé da Fortaleza e Rio Curiaú. Macapá: CPAQ/IEPA; DGEO/SEMA, 2003. p. 81104. Disponível em:

$<$ http://webcache.googleusercontent.com/search?q=cache:http://www.iepa.ap.g ov.br/metadados/instituicoes/iepa/projetos/ressacas/documentos/6finalQUALID ADE\%2520DE\%2520AGUA.pdf> Acesso em: 26 jul 2017. 